\title{
Inhibition of collagen I accumulation reduces glomerulosclerosis by a Hic-5-dependent mechanism in experimental diabetic nephropathy
}

\author{
Nick Hornigold', Tim S Johnson², Linghong Huang ${ }^{2}$, John L Haylor ${ }^{2}$, Martin Griffin ${ }^{3}$ and Andrew Mooney ${ }^{4}$
}

Glomerulosclerosis of any cause is characterized by loss of functional glomerular cells and deposition of excessive amounts of interstitial collagens including collagen I. We have previously reported that mesangial cell attachment to collagen I leads to upregulation of Hic-5 in vitro, which mediates mesangial cell apoptosis. Furthermore, glomerular Hic-5 expression was increased during the progression of experimental glomerulosclerosis. We hypothesized that reducing collagen I accumulation in glomerulosclerosis would in turn lower Hic-5 expression, reducing mesangial cell apoptosis, and thus maintaining glomerular integrity. We examined archive renal tissue from rats undergoing experimental diabetic glomerulosclerosis, treated with the transglutaminase-2 inhibitor NTU281. Untreated animals exhibited increased glomerular collagen I accumulation, associated with increased glomerular Hic-5 expression, apoptosis, and mesangial myofibroblast transdifferentiation characterized by $\alpha$-smooth muscle actin ( $\alpha$-SMA) expression. NTU281 treatment reduced glomerular collagen I accumulation, Hic-5 and $\alpha$-SMA expression, and apoptosis. Proteinurea and serum creatinine levels were significantly reduced in animals with reduced Hic-5 expression. In vitro studies of Hic-5 knockdown or overexpression show that mesangial cell apoptosis and expression of both $\alpha$-SMA and collagen I are Hic-5 dependent. Together, these data suggest that there exists, in vitro and in vivo, a positive feedback loop whereby increased levels of collagen I lead to increased mesangial Hic-5 expression favoring not only increased apoptosis, but also mesangial myofibroblast transdifferentiation and increased collagen I expression. Prevention of collagen I accumulation interrupts this Hic-5-dependent positive feedback loop, preserving glomerular architecture, cellular phenotype, and function. Laboratory Investigation (2013) 93, 553-565; doi:10.1038/labinvest.2013.42; published online 18 March 2013

KEYWORDS: collagen I; glomerulosclerosis; Hic-5; mesangial cell

Glomerular scarring following inflammation is an untreatable disease process accounting for up to $50 \%$ of cases of chronic renal failure requiring dialysis. ${ }^{1}$ Regardless of the initiating cause, glomeruli undergo a stereotypical response to injury. In the glomerular mesangium, this is characterized by the accumulation of abnormal extracellular matrix $(\mathrm{ECM}){ }^{2}$ as well as mesangial cell transdifferentiation to a myofibroblast-like phenotype $^{3}$ that often follows transient mesangial cell proliferation. ${ }^{4}$ In addition to the excess accumulation of collagen IV (a normal constituent of glomerular ECM), fibrillar collagens I and III are progressively deposited in the glomeruli. Normally restricted to the interstitium, collagen I is only detectable in trace amounts in normal glomeruli, but is highly upregulated during glomerulosclerosis. ${ }^{5}$
We have previously reported the consequences of mesangial cell attachment to normal and abnormal ECM proteins in vitro. ${ }^{6}$ Using a proteomic approach, we identified changes in expression of several proteins in mesangial cells, including the upregulation of the protein Hic-5. Hic-5 contains 4 zinc-finger LIM domains, and has been described in multiple protein-protein interactions. ${ }^{7-14}$ It has also been shown to have a role in signal transduction in a variety of cell types, shuttling between nucleus, cytoplasm, and focal adhesions, and is the human homolog of the lepidopteran death-associated LIM protein, DALP. ${ }^{15}$ We demonstrated that mesangial cells attaching to collagen I showed increased Hic-5 expression, compared with cells attaching to the normal mesangial ECM protein, collagen IV. This

\footnotetext{
${ }^{1}$ CRUK Clinical Research Centre, St James's University Hospital, Leeds, UK; ${ }^{2}$ Sheffield Kidney Institute, Northern General Hospital, Sheffield, UK; ${ }^{3}$ School of Life \& Health Sciences, Aston University, Birmingham, UK and ${ }^{4}$ Renal Unit, St James's University Hospital, Leeds, UK

Correspondence: Dr N Hornigold, PhD, St James's University Hospital, CRUK Clinical Research Centre, Beckett Street, Leeds, LS9 7TF, UK.

E-mail: j.n.a.hornigold@leeds.ac.uk

Received 20 June 2012; revised 23 December 2012; accepted 16 January 2013
} 
upregulation of Hic-5 was associated with increased susceptibility to apoptosis. In vivo, there is normally no glomerular Hic-5 expression, but Hic-5 is expressed in diseased glomeruli in a rat model of glomerulosclerosis following subtotal nephrectomy. ${ }^{6}$

Critical to the accumulation of excessive fibrillar collagens, including collagen I, within the glomerular ECM is the enzyme transglutaminase-2 (TG-2). ${ }^{16}$ TG-2 catalyzes the formation of a protein crosslink product, $\varepsilon$ - $(\gamma$-glutamyl $)$ lysine, leading to stable, proteolysis-resistant intra- and intermolecular bonds in ECM proteins. ${ }^{17}$ This causes an alteration of ECM protein homeostasis, leading to increased deposition of ECM proteins in glomerular mesangial and basement membrane as well as a matrix resistant to proteolytic decay. ${ }^{18}$ Recent studies of an inhibitor of TG-2 (NTU281) in experimental glomerular disease leading to glomerulosclerosis have shown not only a reduction in ECM protein levels, including collagen I, but also a reduction in glomerular fibroblast transformation and preservation of glomerular architecture. ${ }^{19,20}$ The mechanisms linking these latter findings to the changed ECM have hitherto been unclear.

We theorized that mesangial phenotypic changes seen in glomerular disease are mediated through glomerular cell Hic-5 expression, resulting from mesangial cell attachment to collagen I. We furthermore hypothesized that it would be possible to disrupt this pathway by reducing collagen I deposition utilizing TG-2 inhibition. Therefore, we studied Hic-5 levels, glomerular cell count, rates of apoptosis, mesangial $\alpha$-smooth muscle actin ( $\alpha$-SMA) expression (the marker of myofibroblast transdifferentiation ${ }^{3}$ ), and collagen I deposition in archive tissue from a rat model of diabetic nephropathy treated with a TG-2 inhibitor. In this model the insulin-producing pancreatic $\beta$-cells are targeted using the toxin streptozotocin (STZ) to which they are particularly susceptible. We undertook double-staining immunohistochemistry to examine whether these proteins colocalize within diseased glomeruli, and also to examine the correlation between Hic-5 protein expression, serum creatinine, and proteinuria. Finally, to confirm that this process was dependent on Hic-5, we investigated in vitro cultures of mesangial cells with siRNA knockdown and forced overexpression of Hic-5 to study whether expression of collagen I and $\alpha$-SMA was altered in these cells.

\section{MATERIALS AND METHODS Materials}

Unless otherwise stated, reagents were obtained from Sigma (Gillingham, UK) and VWR (Poole, UK).

The antibodies Hic-5 (ab42476), Col-1 (ab6308), and $\alpha$-SMA (ab32575 and ab7817) were from Abcam (Cambridge, UK).

The rat mesangial cell line (RMC) was provided by Dr Kitamura (UCL). ${ }^{21-24}$ Hic-5 siRNA knockdown RMC cells and scrambled control siRNA-transfected cells have been previously made and characterized in this laboratory. ${ }^{6}$
pCMV-Hic5A was a kind gift by Dr Peter Laslo (University of Leeds).

\section{Cell Culture}

Cells were cultured in DMEM/F-12 (50:50; Gibco) with 10\% $\mathrm{v} / \mathrm{v}$ fetal calf serum (Harlan Sera Lab), $2 \mathrm{~mm}$ L-glutamine in $5 \% \mathrm{CO}_{2}$ at $37^{\circ} \mathrm{C}$. Cells were discarded after a maximum of 10 passages from initial subculture. Mesangial morphology was regularly checked. ${ }^{25}$ Where necessary, NTU281 was added to cell media at a concentration of $50 \mathrm{ng} / \mathrm{ml}$. Transfection of pCMV-Hic-5A into mesangial cells was undertaken by firstly lipofection into packaging cell line PhoenixA using siPORT (Ambion). After $24 \mathrm{~h}$, medium containing viral particles was harvested and applied to RMC cells for $4 \mathrm{~h}$. Selection was started after a further $24 \mathrm{~h}$.

\section{NTU281 Activity Assay}

The ability of NTU281 to inhibit transglutaminase activity was tested by standard biochemical means using an assay of incorporation of biotin-conjugated cadavrine onto fibronectin. Briefly, wells were coated with fibronectin overnight. Cells were plated at $8 \times 10^{4}$ per well in serum-free medium containing $0.1 \mathrm{mM}$ biotin-cadaverine. After $1 \mathrm{~h}$, cells were lysed and the reaction stopped with $5 \mathrm{mM}$ EDTA. Wells were washed and incubated with HRP-conjugated streptavidin, and the reaction products were visualized with tetramethylbenzidine.

\section{Immunoblotting}

Lysates were prepared in Laemmli buffer $(62.5 \mathrm{mM}$ Tris- $\mathrm{HCl}$, $\mathrm{pH}$ 6.8, 10\% v/v glycerol, 2\% w/v SDS, 5\% v/v 2-mercaptoethanol, and a trace of bromophenol blue) following $16 \mathrm{~h}$ of subculture on the different substrates. Using SDS-PAGE, $2 \mu \mathrm{g}$ of protein was separated in $25 \mathrm{mM}$ Tris, $192 \mathrm{mM}$ glycine, and $0.1 \% \mathrm{w} / \mathrm{v}$ SDS, and transferred onto Hybond-C Super (GE Healthcare). Primary antibody was applied in TBS/Tween $1 \% \mathrm{w} / \mathrm{v}$ non-fat milk powder for $2 \mathrm{~h}$ at room temperature. Dako Envision ${ }^{\mathrm{TM}}+\mathrm{HRP}$ (Dakocytomation) detection system (diluted 1:200 v/v in TBS/Tween 5\% w/v non-fat milk powder) was applied for $1 \mathrm{~h}$. Antibody binding was detected using SuperSignal West Dura (Pierce), followed by exposure to Kodak Biomax MS film. Relative protein abundance was estimated by densitometry on scanned 12-bit images from a Personal Densitometer SI (GE Healthcare) using ImageQuant software.

\section{Real-Time PCR}

mRNA was isolated using RNeasy Mini Kit (Qiagen). The cDNA was made using Superscript III reverse transcriptase (Invitrogen). Real-time PCR was carried out using Taqman Gene Expression Assays Rn00801649_g1 (Colla1) and Rn99999916_sI (GAPDH), and Taqman Universal PCR Master Mix on a 7500 Real Time PCR System (Applied Biosystems). All reactions were carried out according to the manufacturer's instructions. Analysis was by the $\Delta \Delta \mathrm{Ct}$ method. 


\section{Diabetic Nephropathy Model}

NTU281 was synthesized according to published methods. ${ }^{16}$ The diabetic nephropathy model was prepared as previously described. ${ }^{19}$ Briefly, male Wistar Han rats were subjected to right uninephrectomy and, 7 days later, hyperglycemia induced by tail vein injection of STZ $(35 \mathrm{mg} / \mathrm{kg}$ in citrate buffer $\mathrm{pH}$ 4). Control animals received vehicle injection alone. An early morning blood glucose level of $>10 \mathrm{mmol} / \mathrm{l}$ at 1 week after STZ injection was considered diabetic. Blood glucose was controlled between 10 and $25 \mathrm{mmol} / \mathrm{l}$ using insulin implants (Research Pack; LinShin, Toronto, Ontario, Canada). Remaining kidneys were cannulated to deliver NTU281 $(2.5 \mu \mathrm{l} / \mathrm{h}$ of $50 \mathrm{mmol} / \mathrm{l})$, or vehicle alone, to within the renal parenchyma, using osmotic pumps. Rats were allowed free access to standard rat chow (Labsure, Cambridge, UK) and tap water. At 1, 4, and 8 months after STZ injection, rats were killed and kidneys removed from both diabetic (NTU281 treated and untreated) and control animals. Serum creatinine was measured by standard autoanalyzer technique and 24-h albuminuria by using the Bethyl Laboratories rat albumin ELISA kit (BioGnosis, Halisham, UK) following the manufacturer's instructions. All procedures were carried out under license according to regulations laid down by Her Majesty's Government, UK (Animal Scientific Procedures Act, 1986).

\section{Immunohistochemistry}

Paraffin-embedded sections $(4 \mu \mathrm{m})$ were dewaxed and rehydrated. Staining was carried out by standard methods. For single staining, antigen retrieval was performed by boiling in $10 \mathrm{mM}$ sodium citrate, $\mathrm{pH} 6.0$ (20 min). Primary antibody was applied at $5 \mathrm{mg} / \mathrm{ml}$ for $2 \mathrm{~h}$ (Hic-5, $\alpha$-SMA) or at $4{ }^{\circ} \mathrm{C}$ for $16 \mathrm{~h}$ (collagen I). Dako Envision + HRP based detection system was applied for $1 \mathrm{~h}$ and developed with diaminobenzidine (DAB). For double staining, the $\mathrm{X}$-Cell Plus multiplex detection kit 2 (Menapath) was used, according to the manufacturer's instructions. Detection was with $\mathrm{DAB}$ and Vulcan fast red. Immunostaining with preimmune serum showed no staining. For each animal, 25 consecutive glomerular cross-sections were examined. Glomeruli were scored for intensity of staining using a Zeiss Axioplan microscope, at $\times 250$ magnification by a blinded observer on a semiquantitative $0-5$ scale. ApopTag peroxidase in situ apoptosis detection kit (Millipore) was used according to the manufacturer's instructions. Apoptotic bodies were identified by light microscopy analysis of 25 consecutive glomerular cross-sections for each animal by a blinded observer as previously described using morphological criteria. ${ }^{26,27}$ Staining sections with periodic acid/Schiff's reagent (PAS) was carried out by standard methods, staining in $1 \%$ periodic acid for $10 \mathrm{~min}$ and with Schiff's reagent for $20 \mathrm{~min}$, followed by counterstaining with hematoxylin. In all cases, 25 consecutive glomeruli were scored for each animal as previously described. ${ }^{26}$

\section{Colorimetric Analysis}

Photomicrographs were imported into Adobe Photoshop CS5 v12.1 $\times 64$. Color spectral (red/blue/green) analysis was done on cytoplasmic regions of glomerular cells from tissue sections stained with only Vulcan Red, only DAB, or both. Staining conditions were compared in each color channel. Unpaired Student's $t$-test showed that each staining condition could be uniquely distinguished. In all, 20 consecutive randomly selected cells were analyzed for each condition of Hic-5 + SMA, Hic-5 + collagen I, and SMA + collagen I, and compared using the color spectrum criteria above to confirm colocalization within cells. Student's unpaired $t$-test with nonidentical variance was used to analyze differences comparing cells from double-stained sections with cells from single-stained sections.

\section{Statistical Analysis}

Collagen I expression in mesangial cells was compared using the Wilcoxon test. For immunohistochemistry results, an ANOVA test indicated a significant difference between conditions. A two2-sample $t$-test was used to perform pair-wise comparisons between conditions, correcting for multiple testing using the Bonferroni method. Multiple regression analysis was used to test for correlation between Hic5 and other variables, and Pearson's coefficient of determination calculated.

\section{RESULTS}

\section{Reduced Collagen I Expression in Experimental Diabetic Glomerulosclerosis Is Associated with Reduced Hic-5 Expression}

Reducing glomerular mesangial ECM accumulation by TG-2 inhibition in experimental diabetic glomerulosclerosis has been shown to be highly beneficial, almost completely preserving kidney function. ${ }^{19}$ In this model the glomerular scarring index increases by more than twofold in diabetic animals at 4 months, rising to greater than fivefold by 8 months. In contrast, diabetic animals treated with TG-2 inhibition show no significant increase in glomerular scarring at either 4 or 8 months, and their glomerular architecture is seen to remain largely intact.

In these studies, diabetes was induced in 12 uninephrectomized rats using Streptozotocin. Then, six rats were treated with the pan TG inhibitor NTU281 from induction. Diabetic and NTU281-treated diabetic rats, plus uninephrectomy controls, were killed on days 30,120 , and 240 after induction. Kidney sections from these animals were immunostained for collagen I and Hic-5. For each animal, 25 consecutive glomerular cross-sections were examined. Staining was quantified by a blinded observer on a $0-5$ semiquantitative scale. Rats subjected to uninephrectomy as well as normal rats treated with only NTU281 were examined at 240 days. These two controls showed no significant differences from normal control animals and thus for clarity, information is not presented on these groups. 
Collagen I expression was very low in control animals, but its expression rose significantly in diabetic animals, showing a fivefold increase at day 240 (Figure 1a and c) particularly within the mesangial matrix (Figure 1b). In animals treated with NTU281, glomerular collagen I overexpression was reduced by $\sim 50 \%$. Quantification of glomerular Hic- 5 showed increased expression in untreated diabetic animals in a similar pattern to collagen I, reaching a 4.5 -fold increase at day 240 (Figure 2). Hic-5 staining was consistent with that previously described during the development of glomerulosclerosis following subtotal nephrectomy. ${ }^{6}$ Glomerular Hic-5 staining in NTU281-treated animals was similar to that in control animals at all time points (Figure $2 \mathrm{a}$ and $\mathrm{b}$ ). Collagen I and Hic-5 levels were shown to be correlated in individual animals $\left(P<0.05, r^{2}=0.65\right.$; Figure $\left.2 c\right)$, with no evidence of any independent effect of either diabetic status $(P=0.26)$ or time $(P=0.41)$.

Additional in vitro experiments were performed to investigate whether there was a direct effect of NTU281 on mesangial cell biology. Cultured mesangial cells were exposed to NTU281 at $50 \mathrm{ng} / \mathrm{ml}$ for $24 \mathrm{~h}$ and assayed for susceptibility to apoptosis, Hic-5 expression, and procollagen I transcription, but no alterations were observed compared with untreated cells (data not shown). NTU281 inhibitory activity was confirmed by testing the reduction in incorporation of biotin-conjugated cadaverine to laminin, both by mesangial cells and exogenous transglutaminase (data not shown).

\section{Reduced Mesangial Hic-5 Expression Is Associated with Reduced Glomerular Apoptosis and Reduced Glomerular $\alpha$-SMA Expression}

Total glomerular cross-sectional cell number and number of apoptotic bodies per glomerular cross-section were counted in 25 consecutive glomeruli from each animal studied (Figure $3 \mathrm{a}$ and $\mathrm{b}$ ). Total glomerular cross-sectional cell counts confirmed the previously reported proliferation in this disease. ${ }^{4}$ This was abrogated in animals that had received NTU281 treatment (Figure 3b). Apoptotic bodies were visualized using morphological changes on PAS- stained sections (Figure 3c) and sections stained using TUNEL that a

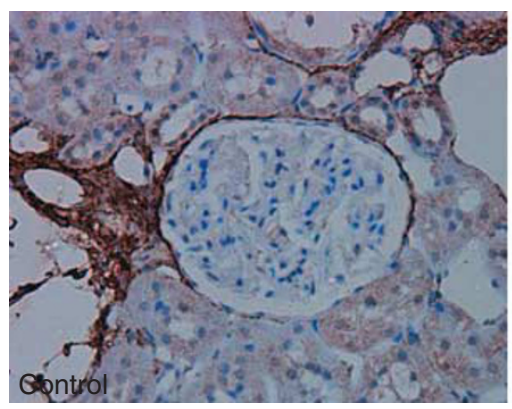

Collagen I

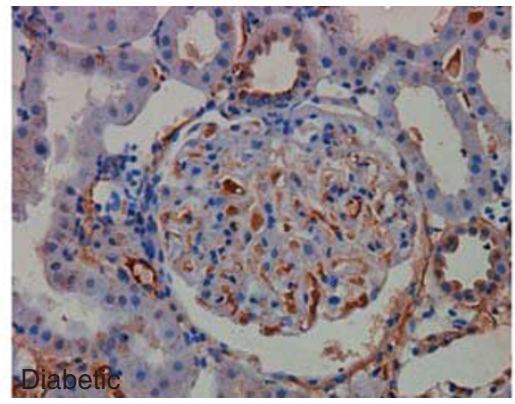

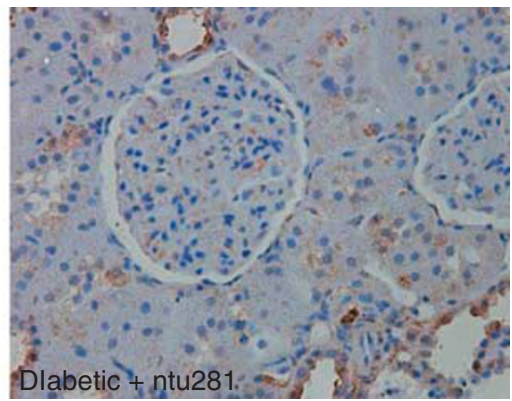

C

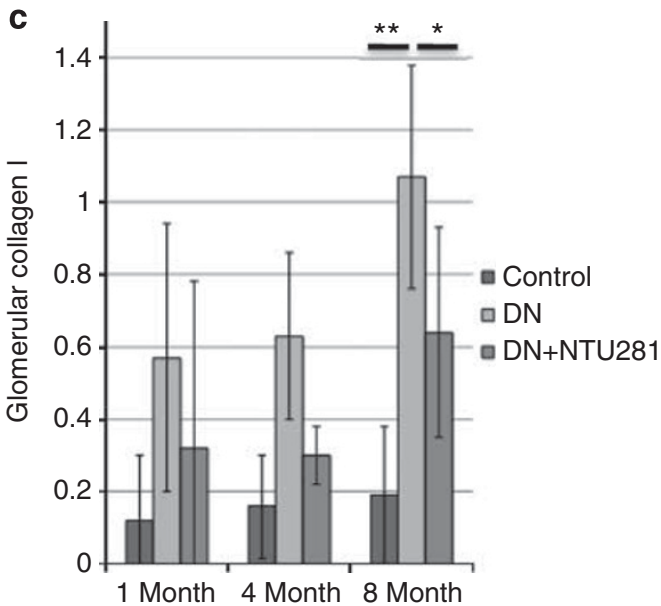

Figure 1 Increases in glomerular collagen I expression in diabetic nephropathy are reduced by TG-2 inhibition. Unilateral nephrectomized male Wistar rats were subjected to streptozotocin-induced diabetes and subsequently treated with the TG-2 inhibitor NTU281 or vehicle. Tissue sections were immunostained for collagen I, and glomerular expression quantified on a 0-5 + scale by a blinded observer for 25 consecutive glomerular cross-sections. (a) Photomicrographs show typical sections for control, diabetic, and NTU281-treated kidneys ( $\times 400$ magnification) at day 240 . (b) Photomicrograph ( $\times 1000$ magnification) showing distribution of collagen in diabetic glomerular cells. (c) Histogram detailing glomerular collagen I staining quantified on a $0-5+$ scale by a blinded observer for 25 consecutive glomerular cross-sections. Significant differences are marked as $* P=0.01$ or ${ }^{* *} P<0.01$. 
a

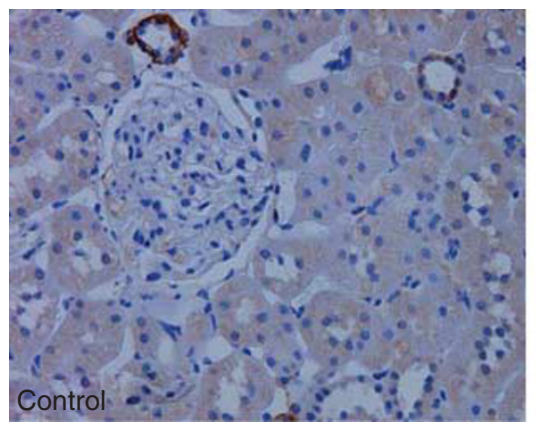

Hic-5

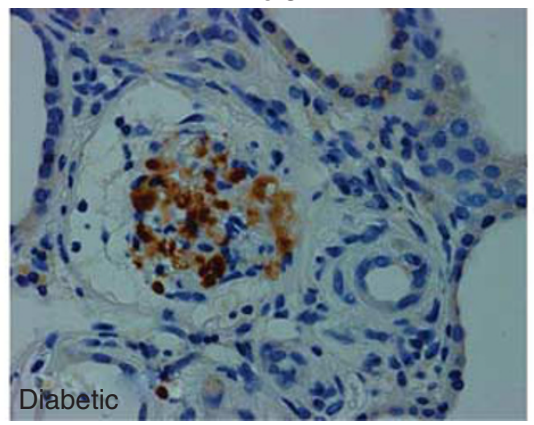

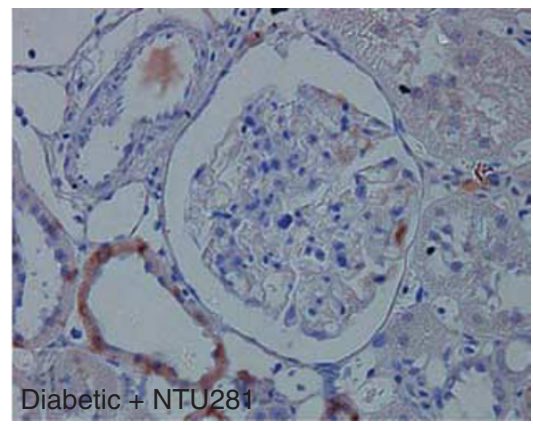

b

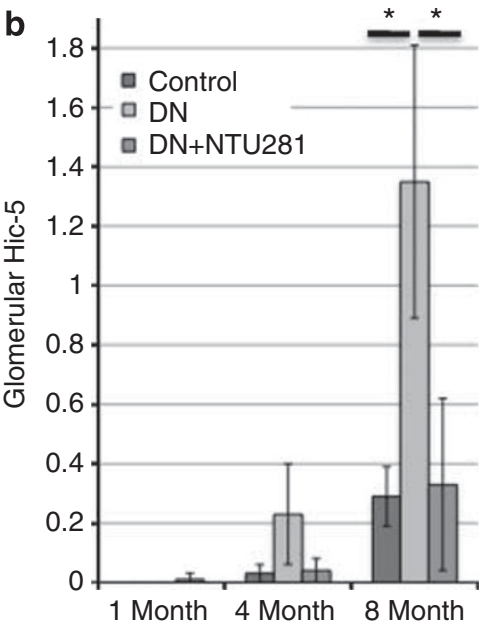

C

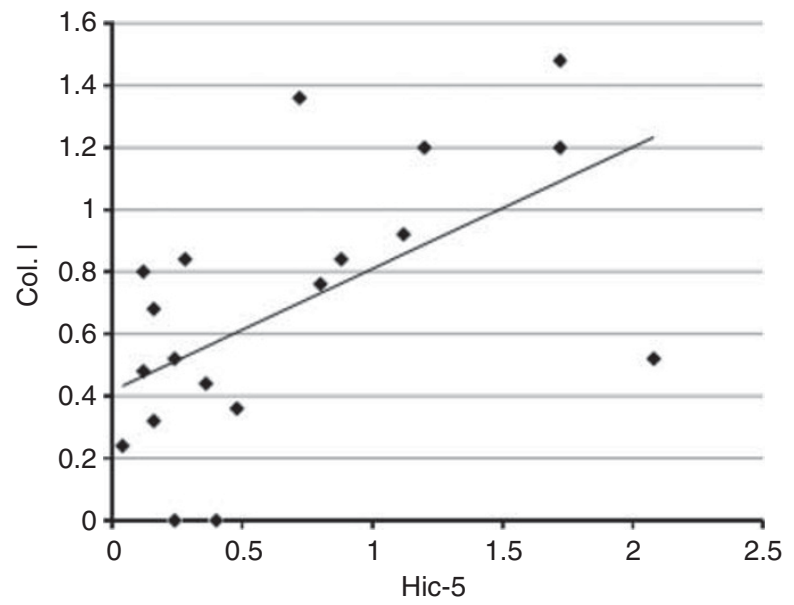

Figure 2 Increases in glomerular Hic-5 expression in diabetic nephropathy are reduced by TG-2 inhibition. STZ-induced diabetes was induced as in Figure 1. Immunostaining was undertaken for Hic-5. (a) Photomicrographs show typical sections for control, diabetic, and NTU281-treated diabetic kidneys at day 240. (b) Quantification of glomerular Hic-5 staining. Significant differences are marked as ${ }^{*} P<0.01$. (c) Glomerular Hic-5 and collagen I expression are correlated $(P<0.05)$. Data for animals at day 240 are shown.

identifies apoptotic cells/bodies by nick-end labeling (Figure 3d). Examination of apoptotic bodies under high power confirmed apoptotic cells to be in the glomerular mesangium, typically surrounded by excessive ECM deposition on PAS staining (Figure 3c). Multiple linear regression showed that both glomerular cell number $(P<0.01$, $\left.r^{2}=0.47\right)$ and apoptosis $\left(P<0.01, r^{2}=0.74\right)$ were related to intensity of Hic-5 staining, and also to the time course of the disease and diabetic status.

Having established that reduction of collagen I accumulation following NTU281 treatment was associated with reduced Hic-5 expression, we also examined the expression of $\alpha$-SMA, as a marker of myofibroblast transdifferentiation, ${ }^{3}$ to determine whether expression of this protein also correlated with glomerular Hic-5 expression. Immunostaining of tissue sections showed that the pattern of staining for $\alpha$-SMA (Figure 4a) followed a pattern similar to that for Hic-5 and collagen I, with levels progressing with the development of glomerulosclerosis (Figure $4 \mathrm{~b}$ ). There was a correlation between Hic-5 expression and $\alpha$-SMA expression $(P<0.001$, $r^{2}=0.72$; Figure $\left.4 \mathrm{c}\right)$, with no evidence for any independent effect of either diabetic status $(P=0.94)$ or time $(P=0.25)$.

\section{Hic-5 Expression Colocalizes with Both Collagen I and $\alpha$-SMA Expression within Sclerotic Glomeruli}

Having established a correlation in the glomerular expression of Hic-5, collagen I, and $\alpha$-SMA in diseased kidneys with increased glomerular apoptosis, we went on to determine if these proteins were colocalized within individual glomeruli. The archive material available proved to be unsuitable for immunofluorescent studies because of autofluorescence. Therefore, sections of renal tissue were examined following double-immunohistochemical staining for Hic-5 and collagen I, Hic- 5 and $\alpha$-SMA, as well as collagen I and $\alpha$-SMA (Figure 5), using Vulcan Red and DAB. In all cases, glomeruli that were negative for Hic- 5 were also seen to be negative for collagen I or $\alpha$-SMA, whereas glomeruli with globally positive staining for Hic-5 were also positive for the other protein. Collagen I and $\alpha$-SMA were similarly seen to be expressed together. In all cases, glomeruli in which these proteins were seen to be coexpressed showed a sclerotic or degenerative phenotype.

To ensure that it was possible to reliably distinguish between double- and single-stained glomerular cells, a colorimetric analysis was undertaken (Figure 5b). Image 

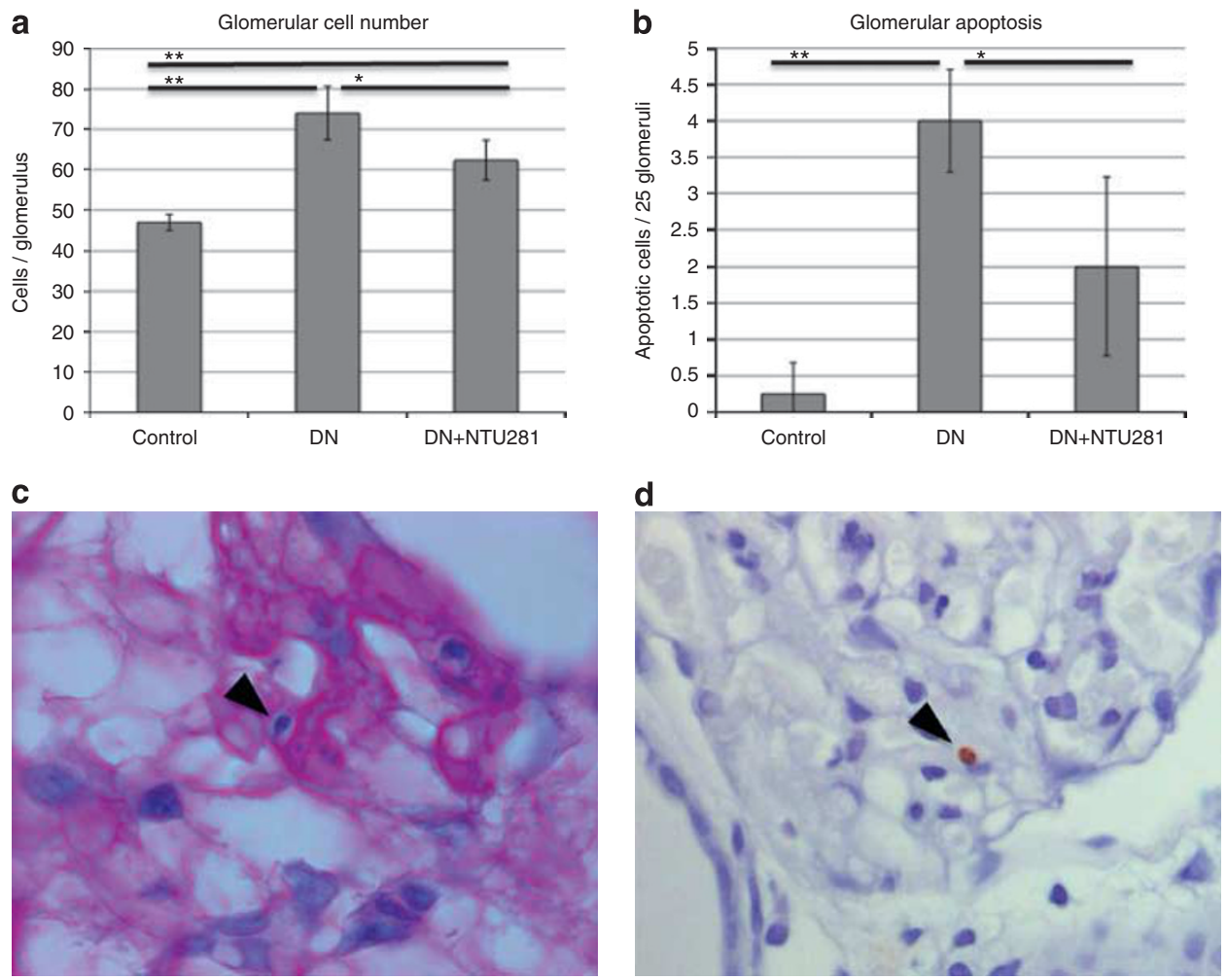

Figure 3 Reduced glomerular Hic-5/collagen I expression in NTU281-treated diabetic kidneys is associated with reduced glomerular hypercellularity and mesangial apoptosis. (a, b) A total of 25 consecutive glomerular cross-sections of control, diabetic, and diabetic + NTU281 kidneys at 240 days after STZ were counted by a blinded observer for glomerular cell number in PAS-stained kidney sections. Examples are shown of apoptotic bodies visualized by PAS staining (c) and by staining with ApopTag (d). Significant differences are marked as $* P<0.05)$ or ${ }^{* *} P<0.01$ ). (c) Photomicrograph ( $\times 400$ magnification) of PAS-stained glomerulus showing typical apoptotic body. (d) Photomicrograph ( $\times 400$ magnification) of apoptotic body stained with ApopTag. Section is counterstained with hematoxylin.

analysis was performed on sections stained with Vulcan Red only, DAB only, and for double-stained sections. The spectral patterns of each stain could be reliably distinguished allowing accurate determination of single or merged staining area $\left({ }^{\star} P<0.001\right)$. Analysis of double-stained sections using these colorimetric criteria confirmed that Hic-5, $\alpha$-SMA, and collagen I were indeed colocalized in cells in diseased glomeruli (Figure $5 \mathrm{c}$ ). In rare cases $(<4 \%)$, staining was seen to be juxtaposed within cells rather than colocalized. In occasional cases, clear segmental glomerular staining was seen, and in these glomeruli double staining was seen in sclerotic areas, whereas other nonsclerotic segments remained double negative (Figure 6).

\section{Increased Hic-5 Expression Correlates with Serum Creatinine and Proteinuria}

Having established morphological and immunohistochemical correlates of Hic-5 expression and glomerulosclerosis, we next investigated whether there was a correlation between Hic-5 expression and functional measures of glomerular integrity. This analysis showed there was also a strong correlation of Hic-5 with serum creatinine and proteinuria (Figure 7), suggesting that the expression of Hic-5 during glomerulosclerosis is associated with glomerular dysfunction. Multiple regression analysis revealed Hic-5 expression as correlating with serum creatinine levels in this model $\left(P<0.001, r^{2}=0.69\right)$, with no evidence of independent effects of diabetic status or time. Similar results following multiple regression analysis were obtained for proteinuria $\left(P<0.01, r^{2}=0.59\right)$, although in this case, the presence of diabetes as well as Hic-5 levels correlated with the degree of proteinuria $(P<0.01)$.

\section{Mesangial Cell Attachment to Collagen I Increases Collagen I Precursor Transcription and $\alpha$-SMA Expression by a Hic-5-Dependent Pathway In Vitro}

To investigate the relationship between these proteins, in vitro studies were undertaken. Proteomic studies using twodimensional polyacrylamide gel electrophoresis (2D PAGE) of changes in the mesangial cell proteome resulting from attachment to collagen I as compared with attachment to collagen IV highlighted increased expression of collagen $\alpha 1$ 
a
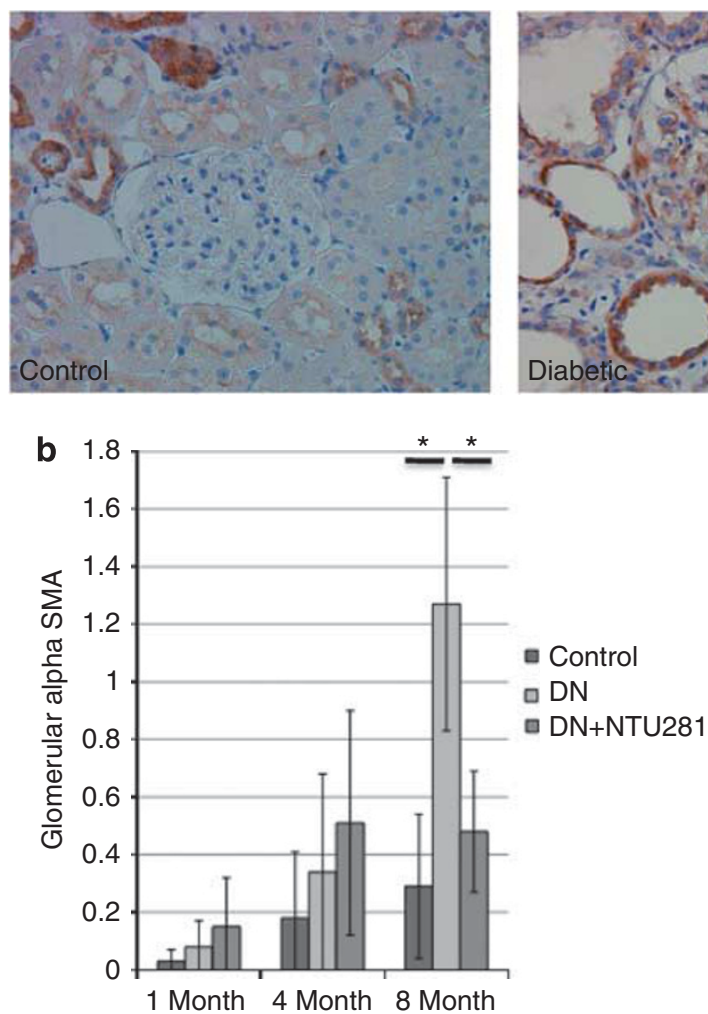

$\alpha \mathrm{SMA}$
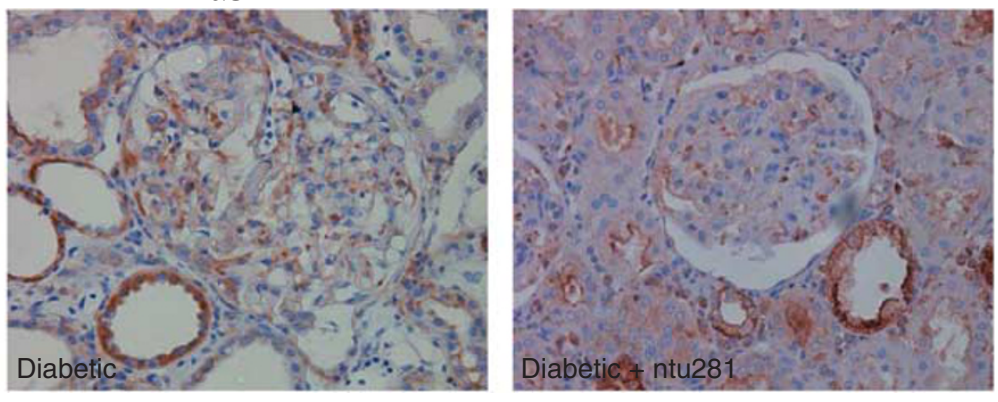

C

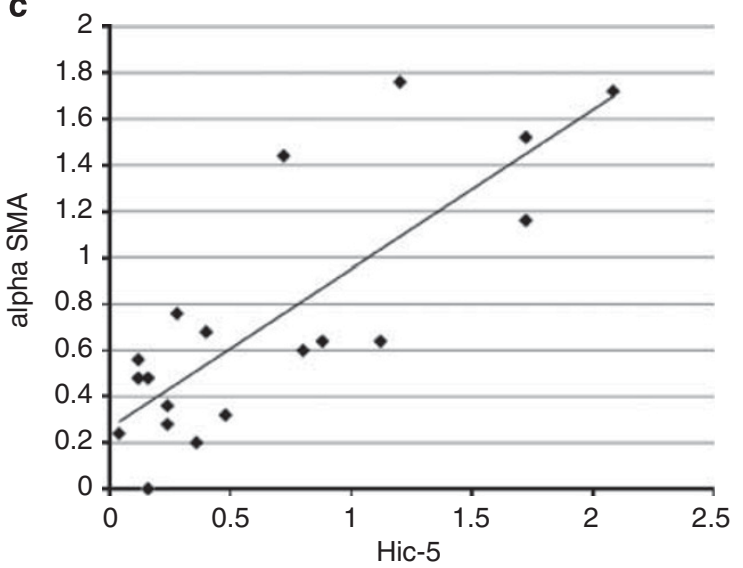

Figure 4 Diabetic nephropathy-induced $\alpha$-SMA expression is reduced in NTU281-treated kidneys. STZ-induced diabetes was induced as in Figure 1. Tissue sections were immunostained for $\alpha$-SMA. (a) Photomicrographs show typical sections for control, diabetic, and NTU281-treated diabetic kidneys at day 240. (b) Quantification of glomerular $\alpha$-SMA expression. Significant differences are marked as ${ }^{*} P<0.01$. (c) Glomerular Hic-5 and $\alpha$-SMA expression were correlated $\left(P<0.001, r^{2}=0.72\right)$. Data for animals at day 240 are shown.

(I) chain precursor (Figure 8a) as well as increased Hic-5 expression. ${ }^{6}$ Tryptic digestion followed by mass spectrometry identified multiple peptides, including two (SLSQQIENIRSPEGSR and NWYISPNPK) specific to the unprocessed pro-collagen I.

To further confirm that collagen $\alpha 1$ (I) precursor increases were not a contamination from the plate coating, RNA was isolated from mesangial cell culture lysates following $16 \mathrm{~h}$ of incubation in tissue culture plates coated with either collagen I or collagen IV. RT-QPCR was performed on wild-type mesangial cells, and also from mesangial cells stably transfected with siRNA to suppress expression of Hic-5. ${ }^{6}$ Scrambled control siRNA-transfected cells were also made and tested. Transcription of collagen $\alpha 1$ (I) chain precursor was significantly upregulated following attachment to collagen I, but this was abolished following attachment to collagen IV or on all plating substrates following siRNA knockdown of Hic-5 (Figure 8b). Scrambled control siRNAtransfected cells showed no changes from wild-type cells. This suggests that there exists a positive feedback loop wherein mesangial cell attachment to collagen I leads to a Hic-5mediated increased transcription of collagen I precursors in vitro. In addition, mesangial cells were transfected with a Hic-5 overexpression construct. Unexpectedly, Hic-5 overexpression was associated with a decrease in the expression of procollagen I mRNA compared with control cells growing on collagen I (Figure 8b).

Cells were tested for susceptibility to apoptosis. Cells with reduced Hic-5 expression, either because of growing on collagen IV or through siRNA knockdown, showed lower levels of apoptosis. Cells overexpressing Hic-5 had normal levels of apoptosis when cultured on collagen I, but when cultured on collagen IV, these cells showed an increased susceptibility to apoptosis (Figure 8c).

Protein lysates from wild-type and Hic-5 knockdown mesangial cells subcultured on collagen I and collagen IV were immunoblotted for $\alpha$-SMA expression. In conditions in which Hic-5 expression is suppressed (by siRNA knockdown or by collagen IV attachment), $\alpha$-SMA expression is reduced (Figure 8d). This implies that upregulation of $\alpha$-SMA (ie, mesangial cell transdifferentiation into a myofibroblast-like cell) as well as upregulation of collagen I is also mediated through Hic-5. Cells overexpressing Hic-5 were also examined. These cells showed a slight upregulation of $\alpha$-SMA in response to increased levels of Hic-5 (Figure 8e). 
a

Hic-5 (VR), Col I (DAB)

Hic-5 (VR), SMA (DAB)

SMA (VR), Col I (DAB)

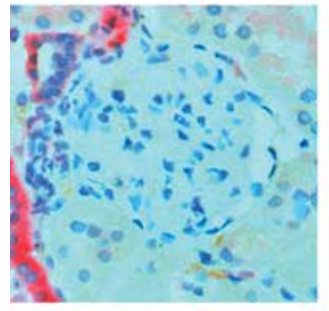

Diabetic
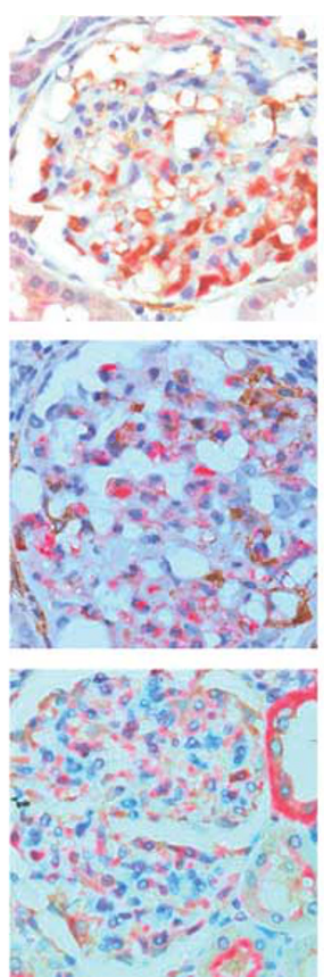

Diabetic (1000x)
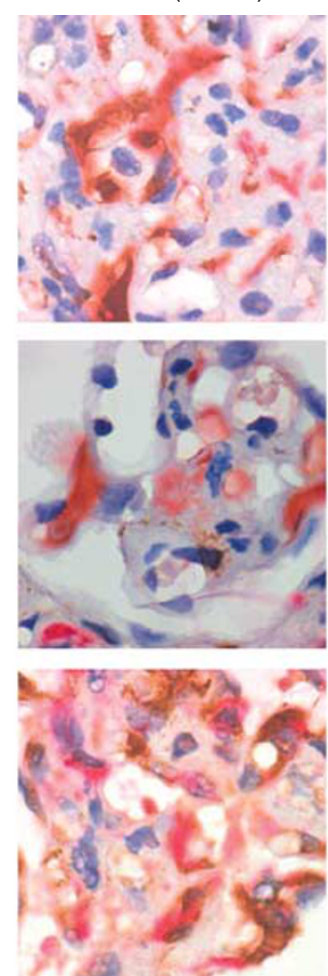

Diabetic + NTU281
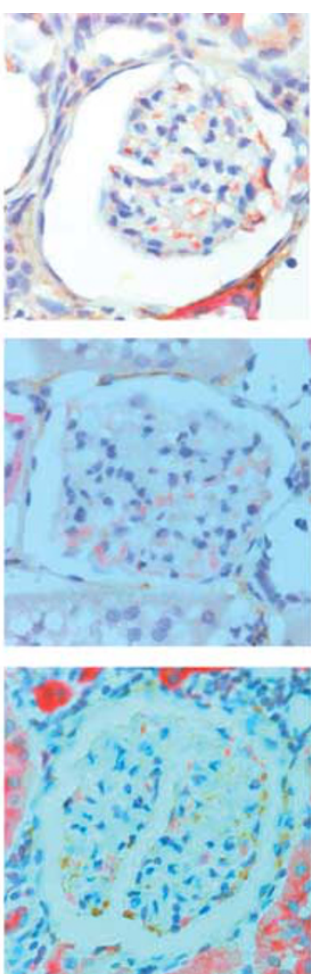

b

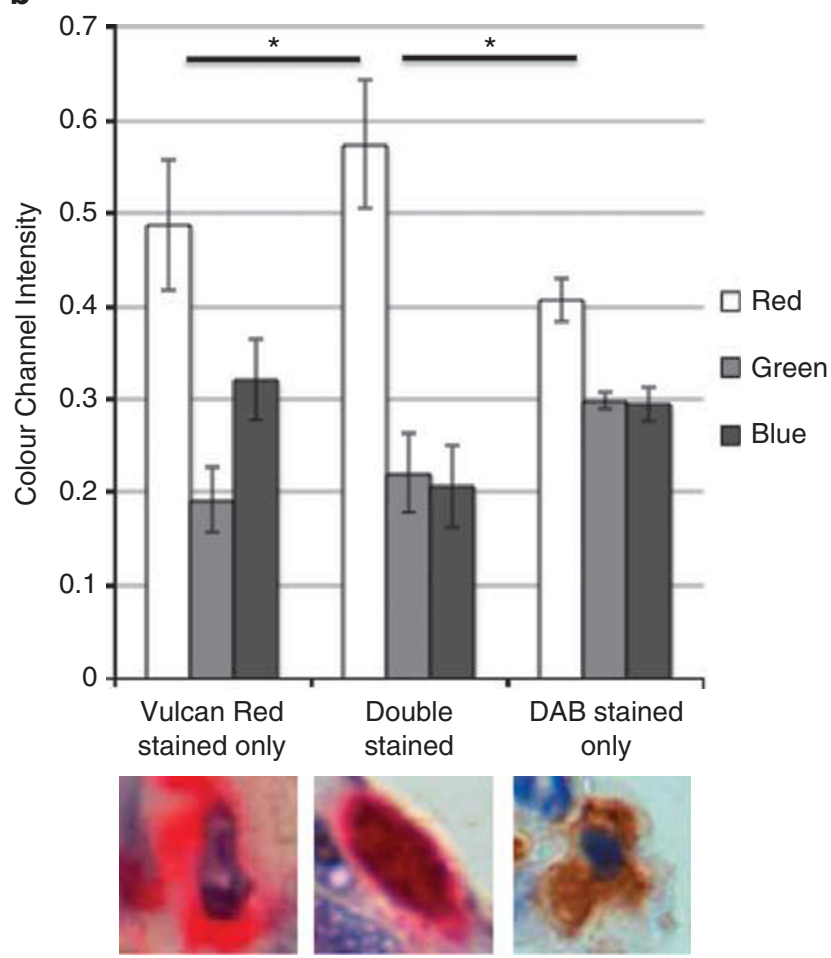

C

Hic- $5+\alpha$ SMA

Double stain

$90 \%$

Hic- 5 only $5 \%$ $\alpha$ SMA only $5 \%$

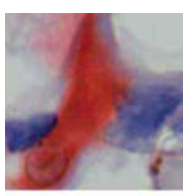

Hic- $5+$ Col I

Double stain

$90 \%$

Hic-5 only $0 \%$

Col I only $0 \%$

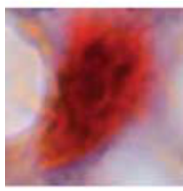

$\alpha \mathrm{SMA}+\mathrm{Col} \mathrm{I}$

Double stain

$90 \%$

aSMA only $0 \%$

Col I only $5 \%$

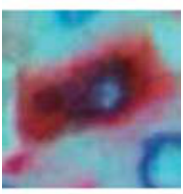

Example of

juxtaposed Hic-5

and $\alpha$ SMA

staining

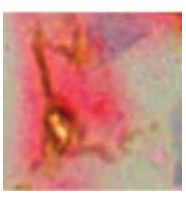

Figure 5 Hic- 5 colocalizes with collagen I and with $\alpha$-SMA in diseased glomeruli. (a) Double staining was undertaken to show colocalization of Hic-5, collagen I, and $\alpha$-SMA within glomeruli from control, diabetic, and NTU281-treated diabetic kidneys. Because of the difficulty of using immunofluorescent techniques with paraffin-embedded tissues, light microscopy was used ( $\times 400$ or $\times 1000$ magnification), staining with diaminobenzadine (DAB, brown) and with vulcan red (VR, red). Typical glomeruli from animals at day 240 are shown. (b) Colorimetric analysis was undertaken to quantify the degree of colocalization of immunohistochemical staining. Color intensity in the red, green, and blue channels was analyzed on sections stained with Vulcan Red only or DAB only, and for double-stained sections. The patterns of red/green/blue color intensity produced could reliably be distinguished $\left({ }^{*} P<0.001\right)$. Examples of cells with single staining for each of Vulcan Red and DAB and double-stained cells are shown below their corresponding histogram. (c) A total of 20 randomly selected consecutive cells were analyzed for each condition of Hic-5 + SMA, Hic-5 + collagen I, and SMA + collagen I, according to these colorimetric criteria. In each case, colocalization was confirmed in at least $90 \%$ of cells. 

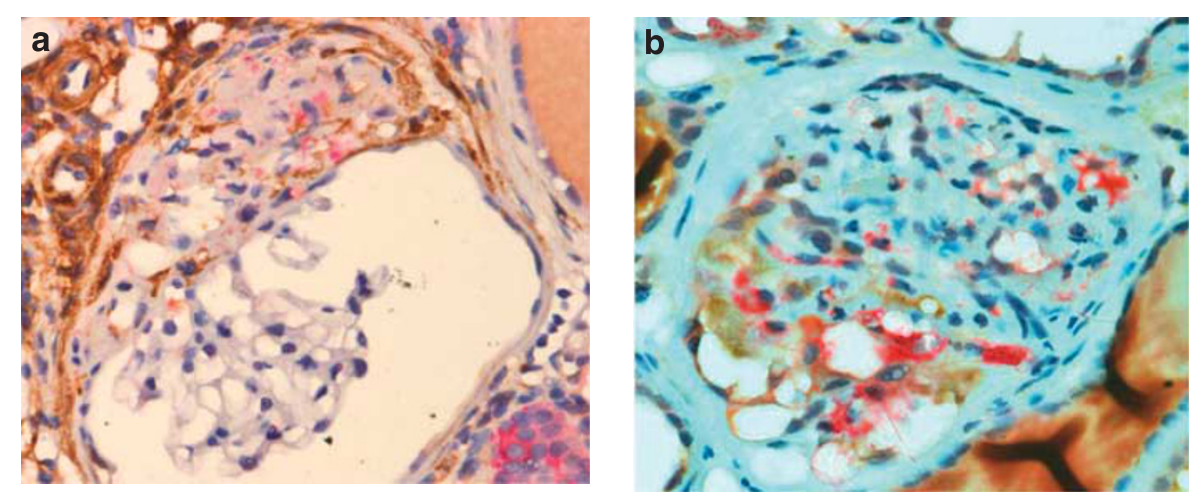

Figure 6 Hic- 5 colocalizes with collagen I and $\alpha$-SMA within segments of affected glomeruli. Although the glomerulosclerosis was in most cases global, occasional examples were seen of glomeruli with segmental lesions. In such examples, Hic- 5 was seen to colocalize with collagen I and $\alpha$-SMA. (a) Glomerulus showing a nonsclerotic, unstained (lower) segment and affected (upper) segment double stained with Hic-5 (VR, red) and $\alpha$-SMA (DAB, brown). (b) Glomerulus showing a nonsclerotic, unstained (upper) segment and affected (lower) segment double stained with Hic-5 (VR, red) and collagen I (DAB, brown).
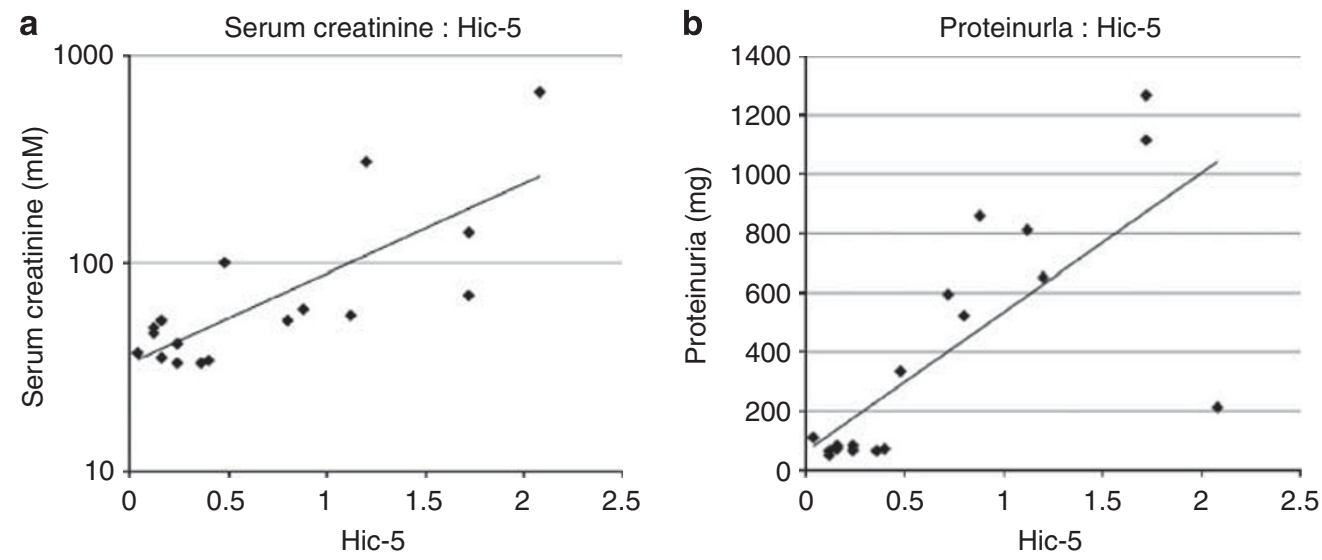

Figure 7 Glomerular Hic-5 expression correlates with serum creatinine and proteinuria. Hic-5 expression shows correlation with serum creatinine $\left(P<0.001, r^{2}=0.69\right)$ and proteinuria $\left(P<0.01, r^{2}=0.59\right)$.

\section{DISCUSSION}

We have previously reported that the presence of increased collagen I expression during experimental glomerulosclerosis is associated with increased mesangial Hic-5 expression. ${ }^{6}$ In our current studies, we demonstrate that in experimental diabetic nephropathy, it is possible to reduce this Hic-5 expression by reducing glomerular collagen I accumulation, which was achieved through inhibition of TG-2. Reduced Hic-5 expression correlated with reduced glomerular cell number, reduced serum creatinine, and reduced proteinuria. This reduced Hic-5 expression was furthermore associated with reduced glomerular mesangial cell apoptosis as well as lower mesangial $\alpha$-SMA expression, suggesting lower transdifferentiation of mesangial cells to a myofibroblastlike phenotype. The effects of mesangial cell Hic-5 expression were confirmed using in vitro siRNA knockdown and Hic-5 overexpression. These experiments established that collagen I attachment and Hic-5 upregulation leads to upregulated $\alpha$-SMA and procollagen I precursor expression by mesangial cells. These data strongly suggest that Hic-5 mediates the altered mesangial cell phenotype seen following attachment to abnormal ECM proteins during experimental diabetic glomerulosclerosis. In addition, upregulation of Hic-5 expression driven by collagen I attachment leads to further collagen I precursor transcription, suggesting a novel Hic-5/ collagen I-dependent, pro-sclerotic positive feedback loop.

Although Hic-5 causes mesangial cells to produce collagen I, and makes them more susceptible to apoptosis, it does not, of itself, cause the cells to undergo apoptosis. It has long been established that in the inflamed glomerulus, both proliferation and apoptosis occur at an increased rate. ${ }^{26}$ The balance between these two processes determines the number of cells in the glomerulus and the outcome of the inflammatory process. Thus, in our current experiment (a model with very little glomerular cellular immigration ${ }^{28}$ ), mesangial cells expressing Hic-5 are able to produce collagen I, and to undergo proliferation, before other factors of cell stress trigger apoptosis, ${ }^{26}$ although overall glomerular cell number increases. Interestingly, mesangial cells attached to collagen IV with forced expression of Hic-5 show increased 

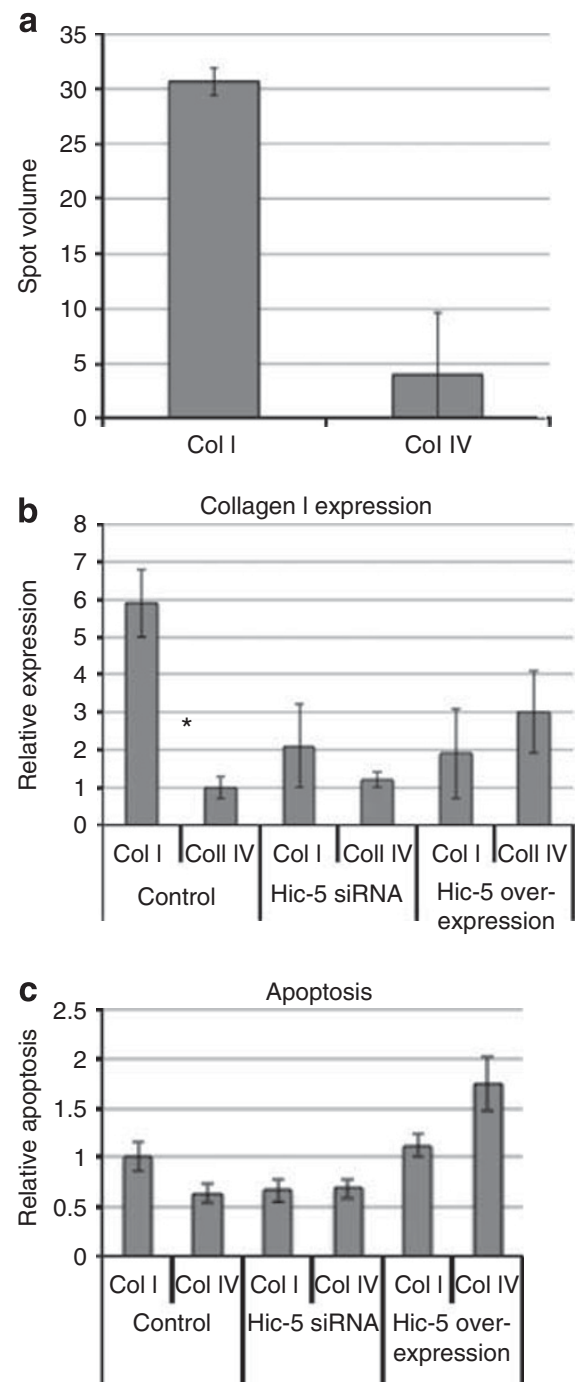
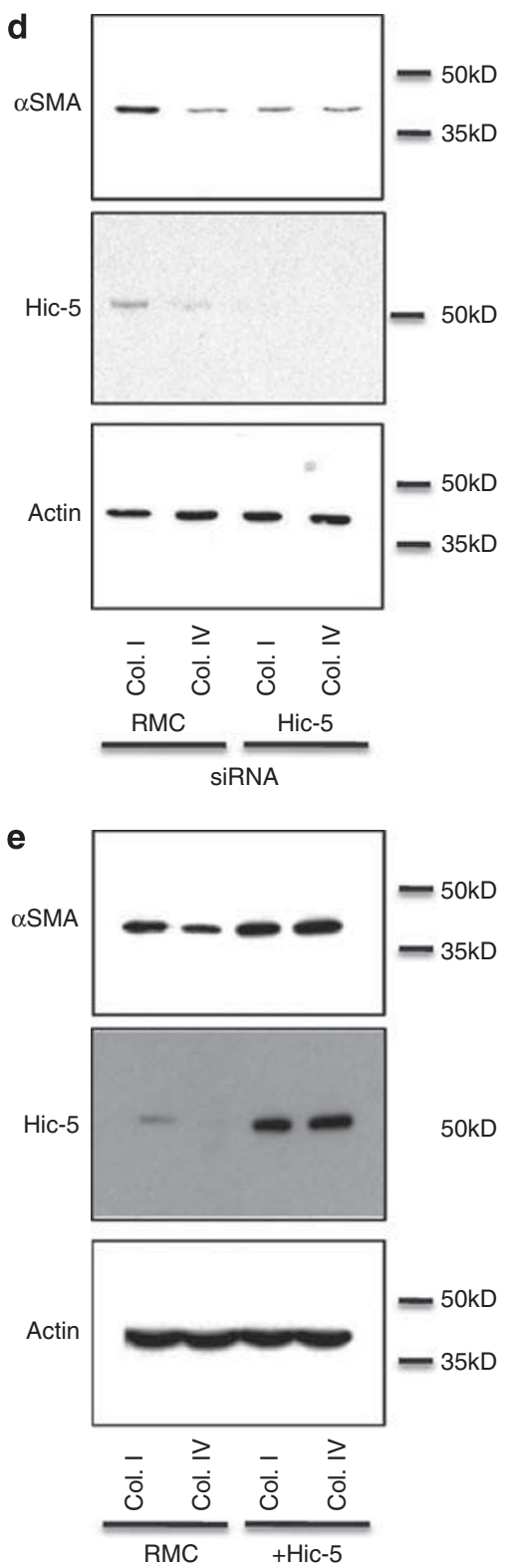

Figure 8 Prepro-collagen $\alpha 1$ (I) and $\alpha$-SMA expression are increased following mesangial cell attachment to collagen I through a Hic-5-dependant mechanism. (a) Spot density of prepro-collagen I expression following mesangial cell attachment to collagen I or collagen IV. Mesangial cell lysates were generated following $16 \mathrm{~h}$ of subculture on collagen I or collagen IV. Following 2D PAGE, spot density was determined by MELANIE software, and protein identity confirmed by MALDI-TOF. (b) RNA was isolated from mesangial cells and from Hic-5 siRNA knockdown cells and Hic-5 overexpressing cells grown in the same conditions as shown in (a) and first-strand cDNA prepared. Pro-collagen 1 levels were measured by real-time QPCR. Samples were run in quadruplicate $\left({ }^{*} P<0.03\right)$. (c) Wild-type mesangial cells, Hic-5 siRNA knockdown cells, and Hic-5 overexpressing cells were tested for susceptibility to apoptosis. Apoptosis was induced by serum starvation. Cells were visualized with acridine orange and morphologically apoptotic cells were counted. The proportion of cells that were apoptotic is shown, relative to the levels seen in control cells on collagen I. Significant differences from the control cells are marked as ${ }^{*} P<0.05$. (d) Lysates were generated from wild-type and Hic-5 knockdown mesangial cells subcultured onto collagen I or collagen IV for $16 \mathrm{~h}$. Lysates were separated by SDS-PAGE, western blotted, and immunoprobed for $\alpha$-SMA, Hic-5, and $\beta$-Actin (loading control). (e) Lysates from wild-type and Hic-5 overexpressing cells were immunoprobed in the same conditions as shown in (d).

susceptibility to apoptosis compared with wild type. The mechanism of this effect is not clear, but is the subject of research in our laboratory.

Our previous studies examined experimental glomerulosclerosis induced by subtotal nephrectomy, ${ }^{27}$ but here we have examined a model of diabetic nephropathy. This confirms that increasing mesangial Hic-5 expression is an effect of glomerulosclerosis per se and is not dependent on the mechanism of injury. Diabetic nephropathy, despite its importance in human disease, is widely acknowledged as a difficult pathological model to reproduce in animals. The current model has been used and published extensively in 
previous papers, and we have used the same archive tissue in these experiments. Variability in severity and time of onset is recognized in this model. ${ }^{19}$ We have not excluded the possibility that cells other than mesangial cells may begin to express Hic-5 in the diseased glomerulus. Indeed, from the distribution of glomerular staining it is likely that a proportion of the Hic-5-positive cells seen are vascular endothelial cells. The final confirmation of the importance of this Hic-5/collagen I-dependent mechanism in the development of glomerular injury will require Hic-5 transgene or knockout experiments, and therefore the recent description of a Hic-5 knockout mouse is of great interest. $^{29}$ The phenotype of this animal is remarkably unaffected considering the high ontological preservation of Hic-5 through diverse species. ${ }^{30,31}$ Nevertheless, the importance of Hic-5 in glomerular disease is emphasized by the recent report describing its upregulation in a range of human glomerular diseases. ${ }^{32}$

It is not possible from these experiments to conclude that this effect of ECM upon mesangial cells is specific to collagen I, rather than attachment to any other ECM component, or indeed to loss of attachment to collagen IV. Although previous work has shown that the $\beta_{1}$ integrin subunit mediates the antiapoptotic effect of collagen IV attachment, the $\alpha$-partner and focal adhesion components through which these ECM signals are transmitted remain unknown. ${ }^{22}$ In these experiments to investigate the effects of reduced collagen I deposition during glomerulosclerosis, we used archive tissue from animals treated with the TG-2 inhibitor NTU281. We expected that NTU281 treatment would affect cells through its action in inhibiting ECM deposition rather than having any direct effects. It has been specifically designed not to be internalized into cells, and it directly targets the active site of TG-2. When tested on cultured mesangial cells in our current experiments, NTU281 had no direct effect on any of the parameters measured. Previous studies have shown that treatment with NTU281 reduces accumulation of not only collagen I, but also of other ECM components. ${ }^{2,5,19,20}$ The relative contribution of each ECM component to these effects is beyond the scope of this study, and therefore we concentrated on the effects of binding to collagen I, as our original observations had demonstrated the importance of this interaction.

Specifically, we show that Hic-5 is necessary for mesangial cell upregulation of pro-collagen I and $\alpha$-SMA in response to collagen I attachment. Following our previous studies, we have now used Hic-5 siRNA knockdown and overexpression models to demonstrate that both this increase in pro-collagen I transcription, and the increases in $\alpha$-SMA expression, are dependent on Hic-5 expression. Whereas $\alpha$-SMA levels were determined by western blotting, pro-collagen I expression was measured using real-time QPCR, because of the difficulty of western blotting these very large proteins as well as avoiding the possibility of contamination from the plating matrix. Pro-collagen I was also seen to be upregulated in our
2D-PAGE and identified by mass-spectrometry of tryptic peptides. The presence here of peptides specific to the unprocessed pro-collagen I is further evidence that this does not represent contamination from the plating matrix. Although the experiments with siRNA knockdown clearly show that Hic-5 is necessary for the prosclerotic phenotype change in mesangial cells, the experiments with Hic-5 overexpression are less clear. This may show that expression of Hic-5 at different levels has different effects, but it may also be an artifact of the unphysiologically high expression of Hic-5 in these cells.

It is also possible that the cellular effects contingent on ECM attachment occur not as a direct result of integrinmediated binding but through a secondary paracrine/autocrine messenger. Transforming growth factor- $\beta$ (TGF- $\beta$ ) has an established role in glomerulosclerosis and might be a candidate for such a messenger. ${ }^{33}$ It is established that mesangial cells secrete this growth factor, ${ }^{34}$ whereas some cell types are reported to express Hic- 5 in response to TGF- $\beta$ stimulation. ${ }^{35}$ Furthermore, TG- 2 recruits TGF- $\beta$ to ECM proteins where it is activated by plasmin, ${ }^{36-38}$ and hence it is possible that the effects observed in these experiments were due to non-ECM effects of TG-2 inhibition. However, although NTU281 might therefore reduce TGF- $\beta$ recruitment to the ECM, previous studies of NTU281treated animals suggested that the major effects seen were not due to altered TGF- $\beta$ actions. ${ }^{20}$ The role of TGF- $\beta$ as a potential effector of Hic-5 has been extensively studied in our laboratory, and is the subject of a further submitted manuscript.

Our previous studies showed that Hic-5 expression was not the only change seen in the mesangial cell proteome following attachment to collagen I, and proteins identified in our previous proteomic experiments might also be implicated in the phenotype change. As a LIM protein, Hic-5 contains 4 double zinc-finger LIM domains, allowing multiple interactions with other proteins. ${ }^{39}$ Other candidates include the serine-protease HTRA1 (downregulated in mesangial cells attaching to collagen I compared with collagen IV), which is known to interact with TGF- $\beta$ family members, ${ }^{40}$ and also to be involved in collagen degradation. ${ }^{41}$ Likewise, we had reported previously alterations in PAI-1 in response to $\mathrm{MC}$ adhesion to collagens. ${ }^{6}$ PAI- 1 is a target of TGF- $\beta$ signalling, ${ }^{42}$ and it modulates the accumulation of ECM. ${ }^{43}$ The role of these other proteins in the regulation of mesangial cell phenotype and pathophysiology are under active investigation in our laboratory.

An important research topic at present is the discovery of biomarkers to improve the monitoring, and hence the treatment of chronic kidney disease. In this context, we considered whether Hic-5, because it displays such a marked upregulation in diabetic kidney disease, could be a candidate for such a biomarker. However, we have previously reported that Hic-5 is highly expressed in some parts of the tubular epithelium, which we identified as the distal tubules. ${ }^{6}$ It is 
also possible, or indeed likely, that this expression would be altered in the disease state (we have experimental evidence in other disease models that suggests that this is the case). We therefore considered that this confounding factor precludes the use of Hic-5 as a biomarker. However, once our continuing studies identify downstream signaling molecules and effectors of Hic-5 in mesangial cells, these are likely to produce ideal candidates for unique biomarkers.

In summary, therefore, we have presented data that show that mesangial cell Hic-5 expression is associated with collagen I attachment in vitro and in vivo, and leads to transformation to a myofibroblast-like phenotype. Blocking collagen I accumulation using TG-2 inhibition reduces mesangial Hic-5 expression, allowing preservation of mesangial phenotype and glomerular integrity. The role of Hic-5 in glomerular scarring is worthy of further investigation.

\section{ACKNOWLEDGEMENTS}

This work was supported by Kidney Research UK (Grant RP18/2/2005), The Special Trustees of Leeds Teaching Hospitals NHS Trust (9/R21/006), and the Yorkshire Kidney Research Fund (PG2009). Assistance with statistical analysis was given by Dr David Cairns of the CRUK Clinical Research Centre, Leeds, UK. We are grateful to Dr Filomena Estevez for assistance with immunohistochemistry. We acknowledge the valuable advice and support given by Professor Rosamonde Banks.

\section{DISCLOSURE/CONFLICT OF INTEREST}

The authors declare no conflict of interest.

1. Schieppati A, Remuzzi G. Chronic renal diseases as a public health problem: epidemiology, social, and economic implications. Kidney Int Suppl 2005;98:S7-S10.

2. Liu Y. Renal fibrosis: new insights into the pathogenesis and therapeutics. Kidney Int 2006;69:213-217.

3. Johnson RJ, Floege J, Yoshimura A, et al. The activated mesangial cell: a glomerular "myofibroblast"? J Am Soc Nephrol 1992;2(10 Suppl): S190-S197.

4. Young BA, Johnson RJ, Alpers CE, et al. Cellular events in the evolution of experimental diabetic nephropathy. Kidney Int 1995;47:935-944.

5. Couchman JR, Beavan LA, McCarthy KJ. Glomerular matrix: synthesis, turnover and role in mesangial expansion. Kidney Int 1994;45: 328-335.

6. Hornigold N, Craven RA, Keen JN, et al. Upregulation of Hic-5 in glomerulosclerosis and its regulation of mesangial cell apoptosis. Kidney Int 2010;77:329-338.

7. Nishiya N, Tachibana K, Shibanuma M, et al. Hic-5-reduced cell spreading on fibronectin: competitive effects between paxillin and Hic-5 through interaction with focal adhesion kinase. Mol Cell Biol 2001;21:5332-5345.

8. Shibanuma M, Kim-Kaneyama JR, Ishino K, et al. Hic-5 communicates between focal adhesions and the nucleus through oxidant-sensitive nuclear export signal. Mol Biol Cell 2003;14:1158-1171.

9. Kim-Kaneyama J, Shibanuma M, Nose K. Transcriptional activation of the c-fos gene by a LIM protein, Hic-5. Biochem Biophys Res Commun 2002;299:360-365.

10. Panetti TS, Hannah DF, Avraamides C, et al. Extracellular matrix molecules regulate endothelial cell migration stimulated by lysophosphatidic acid. J Thromb Haemost 2004;2:1645-1656.

11. Yuminamochi T, Yatomi $Y$, Osada M, et al. Expression of the LIM proteins paxillin and Hic-5 in human tissues. J Histochem Cytochem 2003;51:513-521.

12. Shibanuma $M$, Iwabuchi $Y$, Nose K. Possible involvement of hic-5, a focal adhesion protein, in the differentiation of $\mathrm{C} 2 \mathrm{C} 12$ myoblasts. Cell Struct Funct 2002;27:21-27.
13. Ishino K, Kaneyama, Shibanuma $M$, et al. Specific decrease in the level of Hic-5, a focal adhesion protein, during immortalization of mouse embryonic fibroblasts, and its association with focal adhesion kinase. Journal Cell Biochem 2000;76:411-419.

14. Kim-Kaneyama JR, Wachi N, Sata $\mathrm{M}$, et al. Hic-5, an adaptor protein expressed in vascular smooth muscle cells, modulates the arterial response to injury in vivo. Biochem Biophys Res Commun 2008;376:682-687.

15. Hu $Y$, Cascone PJ, Cheng $L$, et al. Lepidopteran DALP, and its mammalian ortholog $\mathrm{HIC}-5$, function as negative regulators of muscle differentiation. Proc Natl Acad SciUSA 1999;96:10218-10223.

16. Skill NJ, Johnson TS, Coutts IG, et al. Inhibition of transglutaminase activity reduces extracellular matrix accumulation induced by high glucose levels in proximal tubular epithelial cells. J Biol Chem 2004;279:47754-47762.

17. Kleman JP, Aeschlimann D, Paulsson $M$, et al. Transglutaminasecatalyzed cross-linking of fibrils of collagen V/XI in A204 rhabdomyosarcoma cells. Biochemistry 1995;34:13768-13775.

18. Fisher $M$, Jones RA, Huang $L$, et al. Modulation of tissue transglutaminase in tubular epithelial cells alters extracellular matrix levels: a potential mechanism of tissue scarring. Matrix Biol 2009; 28:20-31.

19. Huang L, Haylor JL, Hau Z, et al. Transglutaminase inhibition ameliorates experimental diabetic nephropathy. Kidney Int 2009; 76:383-394.

20. Johnson TS, Fisher M, Haylor JL, et al. Transglutaminase inhibition reduces fibrosis and preserves function in experimental chronic kidney disease. J Am Soc Nephrol 2007;18:3078-3088.

21. Kitamura $\mathrm{M}$, Kawachi $\mathrm{H}$. Creation of an in vivo cytosensor using engineered mesangial cells. Automatic sensing of glomerular inflammation controls transgene activity. J Clin Invest 1997;100:1394-1399.

22. Mooney A, Jackson K, Bacon R, et al. Type IV collagen and laminin regulate glomerular mesangial cell susceptibility to apoptosis via beta(1) integrin-mediated survival signals. Am J Pathol 1999;155: 599-606.

23. Mooney A, Jobson $\mathrm{T}$, Bacon $\mathrm{R}$, et al. Cytokines promote glomerular mesangial cell survival in vitro by stimulus-dependent inhibition of apoptosis. J Immunol 1997;159:3949-3960.

24. Yokoo T, Kitamura M. IL-1beta depresses expression of the 70-kilodalton heat shock protein and sensitizes glomerular cells to oxidant-initiated apoptosis. J Immunol 1997;159:2886-2892.

25. Lovett DH, Sterzel RB. Cell culture approaches to the analysis of glomerular inflammation. Kidney Int 1986;30:246-254.

26. Baker AJ, Mooney A, Hughes J, et al. Mesangial cell apoptosis: the major mechanism for resolution of glomerular hypercellularity in experimental mesangial proliferative nephritis. J Clin Invest 1994; 94:2105-2116.

27. Hornigold N, Craven RA, Keen JN, et al. Upregulation of Hic-5 in glomerulosclerosis and its regulation of mesangial cell apoptosis. Kidney Int 2010;77:329-338.

28. Hartner A, Veelken R, Wittmann M, et al. Effects of diabetes and hypertension on macrophage infiltration and matrix expansion in the rat kidney. BMC Nephrol 2005;6:6.

29. Kim-Kaneyama JR, Takeda N, Sasai A, et al. Hic-5 deficiency enhances mechanosensitive apoptosis and modulates vascular remodeling. J Mol Cell Cardiol 2011;50:77-86.

30. Zhang J, Zhang LX, Meltzer PS, et al. Molecular cloning of human Hic5 , a potential regulator involved in signal transduction and cellular senescence. Mol Carcinog 2000;27:177-183.

31. $\mathrm{Hu} \mathrm{Y}$, Cascone PJ, Cheng $\mathrm{L}$, et al. Lepidopteran DALP, and its mammalian ortholog HIC-5, function as negative regulators of muscle differentiation. Proc Natl Acad Sci USA 1999;96:10218-10223.

32. Suga K, Kondo S, Matsuura S, et al. Glomerular expression of hydrogen peroxide-inducible clone- 5 in human and rat progressive mesangial proliferative glomerulonephritis. Nephron Exp Nephrol 2012;120: e59-e68.

33. Border WA, Noble NA, Yamamoto $T$, et al. Natural inhibitor of transforming growth factor-beta protects against scarring in experimental kidney disease. Nature 1992;360:361-364.

34. Kaname $S$, Uchida $S$, Ogata $E$, et al. Autocrine secretion of transforming growth factor-beta in cultured rat mesangial cells. Kidney Int 1992;42:1319-1327. 
35. Shibanuma M, Mashimo J, Kuroki T, et al. Characterization of the TGF beta 1-inducible hic-5 gene that encodes a putative novel zinc finger protein and its possible involvement in cellular senescence. J Biol Chem 1994;269:26767-26774.

36. Kojima S, Nara K, Rifkin DB. Requirement for transglutaminase in the activation of latent transforming growth factor-beta in bovine endothelial cells. J Cell Biol 1993;121:439-448.

37. Nunes I, Gleizes PE, Metz CN, et al. Latent transforming growth factorbeta binding protein domains involved in activation and transglutaminase-dependent cross-linking of latent transforming growth factor-beta. J Cell Biol 1997;136:1151-1163.

38. Huang L, Haylor JL, Fisher M, et al. Do changes in transglutaminase activity alter latent transforming growth factor beta activation in experimental diabetic nephropathy? Nephrol Dial Transplant 2010;25:3897-3910.
39. Zhang J, Zhang LX, Meltzer PS, et al. Molecular cloning of human Hic-5, a potential regulator involved in signal transduction and cellular senescence. Mol Carcinog 2000;27:177-183.

40. Oka C, Tsujimoto R, Kajikawa M, et al. HtrA1 serine protease inhibits signaling mediated by Tgfbeta family proteins. Development 2004;131:1041-1053.

41. Murwantoko YanoM, Ueta $Y$, Murasaki A, et al. Binding of proteins to the PDZ domain regulates proteolytic activity of HtrA1 serine protease. Biochem J 2004;381(Pt 3):895-904.

42. $\mathrm{Xu} Y$, See WA. Regulation of plasminogen activator activity in transitional carcinoma cell lines by wound site growth factors. Surg Oncol 1994;3:175-185.

43. Ma LJ, Fogo AB. PAl-1 and kidney fibrosis. Front Biosci 2009;14: 2028-2041. 